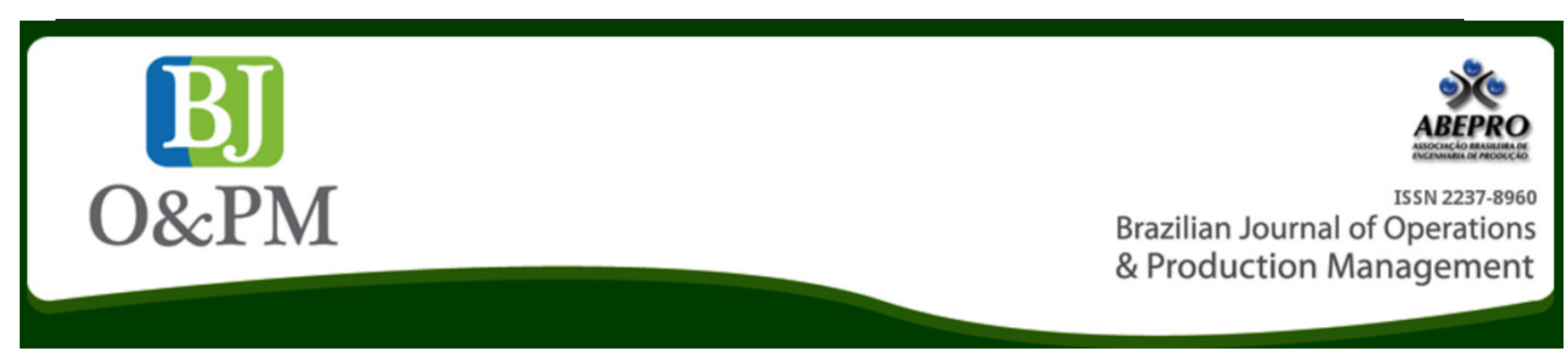

\title{
USING THE INTERNET OF THINGS IN A PRODUCTION PLANNING CONTEXT
}

\author{
Faustino Alarcón ${ }^{a}$; David Perez ${ }^{a}$; Andrés Boza ${ }^{a}$
}

${ }^{\text {a }}$ Polytechnic University of Valencia (UPV) - Valência, VC, Spain

\begin{abstract}
One of the most novel concepts that have been applied to companies in recent years is "Sensing Enterprises". This concept implies a drastic change in the way companies operate. Within the framework of this concept, another necessary and complementary concept arises, the so-called "Internet of Things" concept. It seems evident that the Internet of Things can generally help to improve the functioning of the processes undertaken in companies, particularly one of the key processes; the production planning process. Despite being able to find abundant information on both themes, and the apparent relevance that using the Internet of Things could have for the production planning process, no works that have jointly studied these matters were found. To bridge this gap, the present work intends to reflect on how the characteristics and advantages of the Internet of Things can be put to good use in the production planning process.
\end{abstract}

Keywords: Internet of Things; Production planning; Sensing enterprises

\section{INTRODUCTION}

One of the most novel concepts that have been applied to companies in recent years is "Sensing Enterprises" (SE). This concept entails a drastic change in the way companies operate and, along with other concepts (e.g. liquid, agile, "glocal", sustainable, inventive, humanist, cognitive and communityoriented), seems to mark the future roadmap.

Applying and using the SE concept helps companies to be more sensitive, to become rapidly aware of what is going on around them, and to quickly transfer it to processing centres and decision centres.

Within the framework of this concept, another necessary and complementary concept arises, the so-called "Internet of Things" concept (IoT). The loT permits an interaction between people and things, and at its highest degree of development, the interaction between things and things.

This interaction entails obtaining information from environment, and processing and/or sending this information to other things over the Internet. These other things receive it which, in turn, can set up a new interaction with another thing. In this process, things can basically: acquire and send information over the Internet; process the information they acquire from their environment or which they receive from other things; make decisions; amend their performance or the performance of the system to which they belong.

Nowadays, growing interest is being shown in applying smart products and the loT to production and supply chain management (Meyer et al.,2009). It seems evident that the IoT can help to improve the general operations of the processes undertaken in companies, and one of key process in particular; the production planning process (PPP).

Despite there being abundant information on both themes (IOT and PPP), and the apparent relevance that using the IoT for the PPP could have, no works that have jointly analysed these matters were found. To bridge this gap, the intention of the present work is to reflect on how the advantages that the IoT in the PPP offers can be put to good use. 
To this end, the following section reviews the relevant literature on both themes; IOT and PPP. Section 3 identifies and presents examples of IOT applications in an orderly fashion, and the main benefits of their use for subsequently presenting those aspects that characterise the IOT (IoT characteristics). Finally, Section 4 analyses how the IoT characteristics can be put to the best use in the PPP.

\section{LITERATURE REVIEW}

The interest for the work lies in analysing and understanding how the PPP can improve by using the IoT. Since no previous works that have profoundly dealt with the relation between both these themes were found, we opted to review them all separately. In this way, and depending on the information obtained for each one, the subsequent sections identify and analyze the impact that using the IoT has on the PPP.

Next a literature review on the SE and IoT concepts was done in an attempt to pay attention to the meaning of both concepts, their utility and the advantages/benefits that their use can offer. Then the literature on the PPP was reviewed putting the focus on the activities that comprise it.

\section{1. "Sensing Enterprises" and the Internet of Things (IOT)}

The "Sensing Enterprises" (SE) concept attempts to decentralize the company's smartness for the elements and/ or people comprising it, and who work in it, to move on to a scenario in which the company acts as a complex smart organisation capable of detecting, sensing and reacting to business stimuli (FInES, 2012).

According to Thoma et al., (2013), two recent technologies now permit the SE concept to become a reality: the real-time analysis of large quantities of data and sensors networks that are beginning to complement the already existing RFID technology.

The elements, technologies or sensors that capture information in an SE context are also known as "things", and have given rise to the term "Internet of things". The IoT is a concept that aims to improve forms of communication between humans and the devices (objects) we employ today by using Internet networks. The loT attempts not only to help humans communicate with one another (humans-humans), but also the things are able to exchange information among them, over the Internet, which gives way to new forms of communication: humans-things and things-things (Tan et Koo, 2014).
For Gubbi et al.,2013), the loT is a radical development of today's Internet towards a network of interconnected objects that not only collects information from environment and interacts in the physical world (action/command/ control), but one that also uses existing standards on the Internet to provide information transfer services, analyses, applications and communications.

Some examples of objects that can interact in an IoT context include: radio frequency identification devices (RFID), sensors/actuators, communication machines and devices (Miorandi et al.,2012). Wang (2014) also mentions RFID as well as infrared sensors, global positioning systems (GPSs) and laser scanners. Whitmore et al., (2014) citeRFID and sensors/actuators, and adds mobile phones.

As for the benefits or specific advantages that the loT can provide, Teng Yue (2011) analyses its effect on each link of a food supply chain. This author demonstrates that the IoT can improve the chain's efficiency and the degree of food safety because its use allows real-time communication and it shares accurate information to carry out smart recognition of products, their location, follow-up and monitoring.

The work of Yu Gu etTiaobin Jing (2011) presents three specific IoT applications and their benefits in a fresh agricultural products supply chain. The work of these authors includea table that reflects the improvements obtained from using the loT in the links of this particular supply chain. Other interesting works mention the benefits of the loT; e.g., those by Mao Cuiyun etHan Yuanhang (2010) and Zhou et al.,(2015).

Given the interest of the business processes perspective for the present work, it is worth highlighting the IoT definition proposed by Carretero et García (2014): the IoT is a network of objects connected to the Internet that are perfectly integrated and can be converted into active participants in business processes.

Although the research conducted by Wang (2014) does not follow a clear business processes approach, it mentions some activities that objects perform in an IoT context: capturing information, accurate transmissions and smart processing. This work also mentions some activities that constitute the information and communications exchange protocol for devices connected to the loT: smart identification, positioning, follow-up, monitoring and management.

\subsection{The production planning process (PPP)}

The classic production planning concept, in which many authors coincide about, consists in planning the desired 
future, the means needed and the activities to be performed to cover demand.

Planning is a process for which all those involved in covering demand are organised with time to optimise their work and to obtain the biggest benefit possible for the company. Its main objective is to respond to customer requirements in quality, quantity and due date terms (Meyer et al.,2011) at the lowest possible cost so that available resources are used in the best possible way.

Production planning is defined as a long-term plan for the operations subsystem which includes the objectives to be met, the actions to take and allocation of resources to various products and tasks. All this must be done to pursue meeting the company's objectives within the corporate strategy framework. This entails establishing a Long-Term Capacity and Production Plan.

There are many ways in which the planning process and controlling production can be arranged with a hierarchical approach, even though the essence is always the same. Normally, the next five phases are distinguished: Long-term or strategic planning, Tactical or mid-term planning, Master planning, Components programming and Execution and control.

For Slack et al.,(2004), the activities needed to cover demand can, however, be grouped into the following four tasks: loading, sequencing, programming, and monitoring and control. The first three constitute production planning, while the fourth is known as production control (Meyer et al.,(2011). The monitoring and control task covers the activities performed to react to alterations, which enables deviations from the original plan.

The majority of academic efforts on the production planning and control theme have been made on more sophisticated planning concepts, while monitoring and control have taken second place (Vieira et al.,(2003). The work of Meyer et al.,( (2011) studies using the loT from the production control perspective to overcome drawbacks or alterations in the production plant, such as product errors, production errors, machine failure, quality problems or delivery errors.

\section{APPLICATIONS, BENEFITS AND CHARACTERISTICS OF THE IOT}

This section summarises the applications that the IoT permits companies by means of a literature review, which was done beforehand. With these applications or examples of using the IoT, benefits can be obtained, which are also provided, to summarise the literature review done. Studying the applications, along with the benefits of the IoT, and the other contents obtained from the works we consulted will subsequently permit the identification of IoT characteristics.
Next, we provide the IoT applications cited in the consulted literature, which is not a single or closed list. The IoT can be used to:

- Monitor product quality, which will allow a better control of damaged, lost and stolen products

- Improve and ensure product safety, especially the safety of perishable products, such as food or pharmaceutical products, by means of a powerful real-time traceability system

- Make real-time product information available and for all the supply chain nodes, including customers. This will permit better product follow-up all along the transport route, the exact location and recovery of products, if required, and also information about consumer habits. The participants in the chain will be synchronised with changes in demand. It will also allow customers to decide when to buy and it will offer them ample information about products and producers

- Identify products automatically and accurately classify them

- Know the state that equipment is in and its performance in real time, identify and manage emergences more quickly, and confer autonomy to "things" so they can react.

The benefits that using the IoT can provide companies, as mentioned in the consulted literature, can be grouped as follows:

- More efficiency: The IoT can improve system efficiency in general, and production efficiency in particular, by allowing production to be done according to customer requirements, and will improve the ratio of equipment usage and preparing more realistic plans

- Increased quality and safety: the traceability offered by the loT allows the exact conditions that products must pass through to be known and will, therefore, prevent quality and safety problems

- Facilitate integration: the facilities that the loT offers for supply chain members include information exchange, which favours the chain's integration, coordination and interoperability

- Costs reduction: The IoT helps to reduce inventory levels, improves the control of spoilt products and increases system efficiency, including production, storage, distribution and transport. It improves system management as it makes it easier. It also helps cut down the number of errors and allows less dependence on operators. Allocating routine 
activities at the lowest operational levels will allow humans to be capable of concentrating on strategic matters

- Improved customer response: the IoT can help to achieve more reliable deliveries and a better service level. It is also possible to detect changes in demand more quickly and to make the adjustments required to better cover demand.

According to the consulted information and the interpretation of the authors who wrote the present work, the IoT can be characterised by the following four basic aspects:

1. Reliable and accurate data collection. The sensors and elements (things), designed according to the environment in which they must work, are capable of collecting very reliable and accurate data

2. Capacity to collect a huge quantity of data. The development of information technologies enables huge quantities of data to be stored and processed

3. Rapid data transmission. Today's communication technologies enable huge quantities of data to be transported in a very short time (e.g. wireless technologies), and confer "things" with a real-time response capacity

4. Automated processes. "Things" can become completely autonomous, and entire activities (data collection, calculations and data processing, sending signals with messages, etc.) and whole processes can be performed, including decision making.

\section{USING THE IOT IN THE PPP}

After identifying the IoT characteristics, this section analyses which ones can be applied to the PPP to improve it.

Along the same lines as the work of Meyer et al., (2011), in order to analyse which characteristics the loT can provide to improve the PPP, two main groups were established for the phases, activities or tasks of the PPP, depending on whether its purpose is to: a) develop a plan/programme (Strategic planning, Tactical planning, Master planning and Component programming); or b) run it and control it (Execution and Control). The nature and operation of each group of phases (developing and execution/control), their objectives and, especially the information to be used, will be clearly different.

An IoT application to improve the PPP should, therefore, bear in mind these differences by adapting the performance of "things" to the type of process phases which they are to interact with. After, the use of the IoT is analysed for these two groups of PPP phases or activities: developing plans and executing and controlling these plans.
The information that required to develop plans is basically demand (forecast and/or firm), forecasting the supply capacity of suppliers and the company's capacities (production, assembly, storage, distribution and installation), and forecasting the status of inventories (at the corresponding information aggregation level in each case).

To develop plans, the IoT can contribute reliable and accurate data collected from points of sale and customers (demand), which will fine-tune forecasts and improve the quality of plans. Reliable and accurate data can be essential as far as the company's capacities and the status of the inventories are concerned.

The loT's capacity to collect and work with huge quantities of data will be fundamental to create lists and to calculate forecasts according to the number of articles to be managed. It will also be important for processing information on the company's capacities, depending on the number of sections, human resources, machines and the complexity of the production process.

The possibility that the IoT offers for automating these tasks must be suitably assessed and used to improve efficiency and to reduce errors and costs. As far as rapid data transmission is concerned, the loT characteristic is considered of little relevance to develop plans if we bear in mind the horizons and dates that are usually dealt with, and it is not strictly necessary to acquire input data for real-time plans.

However, for executing and controlling the plan, the IOT characteristic will be extremely valuable for rapid data transmission. To execute and control the plan, it will be necessary to know the plan itself in adequate detail and the performance of all our resources, preferably in real time, so that we can react as soon as possible to incidences or deviations from the plan.

Likewise, the reliable and accurate data collection that the loT offers can be used to send plans and to execute them, and to also follow-up and exactly control their execution. Automation is also considered most important for this case, and the loT performs tedious, hazardous, complex or repetitive tasks. Perhaps the least relevant loT characteristic to execute and control the plan is the capacity to collect a large quantity of data, but what is really necessary in this case is to follow-up what occurs in the plant in real time.

\section{REFERENCES}

Carretero, J. et García J.D. (2014), "The internet of things: Connecting the world", Vol. 18 No.2, pp. 445-447. DOI: 10.1007/s00779-013-0665-z.

FInES (2012). "FInES research roadmap 2025: future internet enterprise systems cluster (FInES)", , available at: 
http://cordis.europa.eu/fp7/ict/enet/documents/finesresearch-roadmap-v30_en.pdf (Access 01/14, 2015)

Gubbi, J., Buyya, R. Marusic, S. and Palaniswami, M. (2013), "Internet of things (IoT): A vision, architectural elements, and future directions", Vol.29 No.7, pp.16451660. DOI: 10.1016/j.future.2013.01.010.

Mao, C. et Han, Y. (2010), "Discussion on the application of internet of things in logistics production management", DOI: 10.1109/ICEE.2010.979

Meyer, G.G., Wortmann J.C. and Szirbik, N.B. (2011), "Production monitoring and control with intelligent products", International Journal of Production Research, Vol.49 No.5, pp.1303-1317. DOI: 10.1080/00207543.2010.518742.

Meyer, G.G., Framling, K. and Holmstrom, J. (2009), "Intelligent products: A survey", Comput.Ind., Vol.60 No.3, pp.137-148.

Miorandi, D., Sicari, S., De Pellegrini, F. and Chlamtac, I. (2012), "Survey internet of things: Vision, applications and research challenges", Vol.10 No.7, pp. 1497-1516. DOI: 10.1016/j.adhoc.2012.02.016.

Slack, N., Chambers, S. and Johnston, R. (2004), "Operations management". Ed., Harlow: Pearson Education.

Tan, J. et Koo, S.G.M. (2014), "A survey of technologies in internet of things", Ed., Marina del Rey, CA. DOI: 10.1109/ DCOSS.2014.45

Teng, Y. (2011), "Internet of things technology application in the food supply chain management", DOI: 10.1109/ ICEBEG.2011.5882613

Thoma, M., Antonescu, A., Mintsi, T. and Braun, T. (2013), "Linked services for enabling interoperability in the sensing enterprise". In M. van Sinderen, P. Oude Luttighuis, E. Folmer \& S. Bosems (Eds.), (pp. 131-144) Springer Berlin Heidelberg. DOI: 10.1007/978-3-642-36796-0_12

Vieira, G.E., Herrmann, J.W. and Lin, E. (2003), "Rescheduling manufacturing systems: A framework of strategies, policies, and methods", Vol.6 No.1, pp.39-62.

Wang, X.F. (2014), "Research on security issues of the internet of things", DOI: 10.4028/www.scientific.net/ AMR.989-994.4261

Whitmore, A., Agarwal, A. and Da, Xu. L. (2014), "The internet of things-A survey of topics and trends", DOI: 10.1007/s10796-014-9489-2.

Yu, G. et Tiaobin, J. (2011), "The IOT research in supply chain management of fresh agricultural products" DOI: 10.1109/AIMSEC.2011.6011477

Zhou, L., Chong, A.Y.L. and Ngai, E.W.T. (2015), "Supply chain management in the era of the internet of things",
International Journal of Production Economics, Vol. 159, pp.1-3. DOI: http://dx.doi.org/10.1016/j.ijpe.2014.11.014. 